\title{
TECNOLOGIA E A EDUCAÇÃO COMO DESENVOLVIMENTO HUMANO
}

\author{
Renato Kraide Soffner \\ Eduardo Oscar de Campos Chaves
}

\begin{abstract}
RESUMO
Existe um novo relacionamento entre o homem e a informação disponível no mundo hoje - e a tecnologia tem um papel a desempenhar neste contexto. A educação pode ser beneficiária deste novo momento da história humana, se puder se valer das tecnologias de informação e comunicação, já disponíveis, para a concepção e implementação de um novo modelo pedagógico, que privilegia a conversão de informação em conhecimento, além de suportar o desenvolvimento de competências e de potencial humano. Entendidas assim, as tecnologias da inteligência (ou de apoio ao desenvolvimento cognitivo) são, na verdade, tecnologias da aprendizagem. Os trabalhos pioneiros de Vannevar Bush em aparatos tecnológicos de tratamento da informação - associados a modelos de pensamento e cognição - e aprimorados pelos seus seguidores, serão os meios de realização de tal modelo inovador.
\end{abstract}

\section{PALAVRAS-CHAVE}

Tecnologias da inteligência; Modelos de educação; Desenvolvimento humano; Competências.

\section{TECHNOLOGY AND EDUCATION AS HUMAN DEVELOPMENT}

\begin{abstract}
There is something new in the relationship between man and the information that is available to him in the present world (last sixty years) - and technology has had, and continues to have, a major and structuring role in bringing about and sustaining this new fact. Education may take advantage of this new phase of the human history, through the use of available information and communication technologies, providing a new pedagogical model that stresses the convertion of information into knowledge, developing competencies and human potential. From this point of view, such intelligence technologies are, in fact, learning technologies. The pioneer work of Vannevar Bush on technological devices for information treatment, improved by his followers, will be the basis for such model.
\end{abstract}

\section{KEYWORDS}

Intelligence technologies; Models of education; Human developing; Competencies 


\title{
INTRODUÇÃO
}

\author{
Fundamental progress cannot be achieved \\ through incremental advances in existing technology. \\ -- John McCarthy
}

Nossos dias testemunham uma nova relação entre o homem e a informação à sua disposição. Neste contexto, a tecnologia tem importante papel a desempenhar, como elemento habilitador deste novo relacionamento.

Em primeiro lugar, se pudéssemos determinar a quantidade de informação per capita, seria correto afirmar que nunca houve tanta informação disponível na história da humanidade. A informação necessária hoje está sempre “na ponta de nossos dedos”, devido às facilidades de manuseio oferecidas pela tecnologia de informação. Em segundo lugar, hoje temos condições de nos valer e apropriar dessas informações com facilidade e eficiência. As tecnologias disponíveis nos permitem capturar, armazenar, organizar, pesquisar, recuperar e transmitir a informação de nosso interesse com extrema eficácia. Em terceiro lugar, temos ferramentas tecnológicas que nos permitem analisar, avaliar e transformar essa informação em conhecimento, colocando-as a bom uso em nossos processos tanto de entendimento e compreensão da realidade como de tomada de decisão e ação. E, em quarto lugar, hoje também possuímos ferramentas tecnológicas de interação e comunicação interpessoal que nos permitem estabelecer e manter contato com outras pessoas, de qualquer canto do mundo, de forma quase instantânea, de modo síncrono ou assíncrono, formando assim redes globais de informação e comunicação e, no processo, comunidades virtuais de interesses afins (entre os quais a aprendizagem), que nos possibilitam discutir criticamente idéias, teorias, ideologias e pontos de vista.

Toda esta informação poderá ser utilizada pelos processos educacionais dentro de um modelo que privilegia sua transformação em conhecimento. Tem sido esta, inclusive, a discussão levada a cabo pelos defensores da área chamada de gestão do conhecimento, muito valorizada, recentemente, pelas empresas e organizações.

Tecnologias de suporte ao desenvolvimento cognitivo, fundamento para a aplicação eficaz da informação em educação, tornam-se verdadeiras tecnologias da aprendizagem. Estas foram criadas, como veremos a seguir, por pioneiros preocupados com o 
emprego da tecnologia no desenvolvimento humano, ou seja, no aumento, ampliação e expansão das capacidades do ser humano (sua inteligência e suas competências). Outra aplicação imaginada seria a de formação de redes globais de informação e comunicação, permitindo o estabelecimento de comunidades de aprendizagem colaborativas.

\section{FERRAMENTAS PARA O PENSAR}

A maior parte desses desenvolvimentos tecnológicos e suas implicações epistemológicas já haviam sido previstos num artigo de Vannevar Bush em 1945 (BUSH, 1991). O impacto dessas idéias e ferramentas na educação pode ser avaliado pelo estudo do processo de desenvolvimento do ser humano que se dá através da aprendizagem, sendo esta entendida como o processo através do qual nos tornamos capazes de fazer (no plano mental, do entendimento e da compreensão, ou material, da tomada de decisão e da ação) aquilo que antes não conseguíamos fazer.

Bush preocupava-se com a quantidade de informação produzida. A segunda guerra estava terminando e intensa pesquisa tecnológica estava produzindo não só a bomba atômica, que iria selar o fim da guerra, mas, também, o primeiro computador eletrônico, o ENIAC (Electronic Numerical Integrator and Calculator), que introduziria uma nova era. Era o início da sociedade da informação, o momento histórico do nascimento dos computadores digitais. Para ele, a tecnologia seria empregada no pensar inteligente, que conduz ao agir inteligente, que é fruto, por sua vez, da decisão inteligente.

Lança, então, a semente de um dispositivo que ele concebia como extremamente importante, especialmente para a educação: através do seu Memex ele imaginava tornar-se possível registrar, acompanhar e até mesmo visualizar todo o processo de construção do pensamento na mente do indivíduo que eventualmente levará ao conhecimento.

Bush via com razoável clareza que o processo de construção do conhecimento envolve não apenas palavras (texto), mas também imagens e sons. Seu dispositivo era, de forma primitiva, multimidiático. 
Aprender, no contexto da informação disponível hoje no mundo, é algo bem diferente do que era ao final da Segunda Guerra Mundial. Em 1945 a informação disponível era escassa e o acesso a ela difícil. Por isso a educação formal das pessoas - realizada nas escolas - se limitava a um processo linear de transmissão de informações (organizadas em matrizes de disciplinas e séries), de professores (que possuíam essas informações) para alunos (que careciam delas), através do ensino (apresentação organizada e simplificada das informações). Aprender era visto como algo passivo, equivalente a absorver e assimilar as informações apresentadas - em geral sem maior entendimento e compreensão e mesmo que não tivéssemos a menor idéia de sua utilidade e aplicação no processo de tomada de decisão e ação no mundo em que nos cabe viver.

O citado novo relacionamento do ser humano com a informação nas últimas décadas tornou essa concepção da educação totalmente anacrônica. É preciso rever o papel da escola nesse processo, em especial diante das inúmeras alternativas de educação não-formal que a tecnologia torna possíveis. A educação que hoje se faz necessária deve ser muito mais voltada para o desenvolvimento de competências - não só as de caráter puramente mental, mas também aquelas que, sem perder seu componente mental, possuem caráter eminentemente mais prático, sendo indispensáveis para a convivência social e para os quefazeres produtivos e profissionais (trabalho), para o uso do tempo livre (lazer), para a aprendizagem constante e permanente (educação). É inegável que todas essas competências têm um núcleo eminentemente cognitivo.

\section{UMA NOVA EDUCAÇÃO}

Uma proposta de educação alicerçada nesta visão de tecnologia pode ser decisiva na promoção do desenvolvimento do ser humano, pela expansão de sua inteligência, tanto individual como coletiva, já que suporta sua aprendizagem, entendida como processo de aquisição de competências - tanto as de caráter puramente mental como aquelas que envolvem a ação e a prática.

As tecnologias hoje disponíveis devem suportar esta nova visão pedagógica, que entende a educação como o processo de desenvolvimento pleno do ser humano, o que exige, 
entre outras premissas, que ele aprenda a pensar e agir de forma inteligente. Essa forma de ver a educação certamente não é nova - mas assume uma importância especial nos dias atuais.

Assim, a escola - organização criada para formalmente promover a educação deve auxiliar seus alunos no desenvolvimento das competências básicas requeridas para se viver em sociedade. Esse modelo de escola deve substituir o modelo voltado quase que exclusivamente para a transmissão de informação - modelo esse que as tecnologias hoje disponíveis tornaram ultrapassado.

O desenvolvimento de competências oferece amplas possibilidades para que o aprendente ${ }^{1}$ se torne auto-suficiente na transformação de dados e informações em conhecimentos, que serão mobilizados pelas várias competências a serem desenvolvidas. Para isso ele recebe, hoje, apoio das chamadas tecnologias da inteligência (LÉVY, 1993) em ambientes que, com a presença da tecnologia, podem ser tornar especialmente ricos em experiências significativas de aprendizagem.

A sociedade atual se caracteriza por tornar possíveis e disponíveis enormes quantidades de informações - mas não se tornou ainda capaz de encontrar formas eficazes e eficientes de ajudar as pessoas a transformar informações em conhecimentos e de traduzir conhecimentos em competências que lhes permitam realizar os seus projetos de vida e, assim, se realizarem a si próprias. Isso só se dá através da educação. Mas educação, nesse contexto, é certamente mais do que simples transmissão de informações através do ensino: é, na verdade, um processo de real preparação para a vida, que acontece na medida em que as pessoas ativamente se envolvem no desenvolvimento das competências requeridas para viver vidas bem sucedidas.

O apoio proporcionado a esse processo pelas novas tecnologias de informação e comunicação pode ser decisivo, em especial no complexo desenvolvimento de inteligências humanas versáteis e flexíveis, capazes de atuar eficaz e eficientemente em ambientes tecnológicos complexos, que requerem intensa interação e cooperação, e, por conseguinte, ferramentas que facilitem a colaboração, seja na aprendizagem, seja no trabalho, seja até mesmo no lazer. Os muitos obstáculos ao desenvolvimento desse tipo de inteligência podem ser reduzidos em quantidade ou diminuídos em dificuldade com o auxílio da tecnologia, assim facilitando o processo de aprendizagem.

\footnotetext{
${ }^{1}$ Discussão baseada em ASSMANN (1998).
} 
A cultura tecnológica em que vivemos pode fazer uma diferença positiva e atuar diretamente no desenvolvimento cognitivo do aprendente. Cabe, a nosso ver, uma crítica ao desenvolvimento tecnológico, do passado ao presente, ao se verificar até que ponto estamos caminhando no rumo desejado, já pensando no futuro. Existe sempre o elo com a educação. A complexidade tecnológica e sua transparência para o ser humano são fatores que determinam bloqueios e limites cognitivos. Extensões naturais para o processo de cognição humana são esperadas. Será que um dia as alcançaremos - e de forma generalizada? Em caso positivo, quando? E como? Será que a mente realmente opera de forma linear e lógica, como tradicionalmente se imaginava, ou será que opera de forma mais associativa, “dando saltos”, em moldes mais semelhantes aos concebidos por Hume ${ }^{2}$ ? Será que o hipertexto é mais natural para a mente humana do que o "texto” de uma demonstração lógico-matemática? E o que dizer dos chamados "agentes mentais", que poderiam explicar a emergência da inteligência, no modelo que Minsky defende em sua sociedade da mente (MINSKY,1988)?

A relação entre a velocidade da inovação tecnológica e o desenvolvimento da cognição humana, em termos de idéias, associações, criatividade, insight, memória e raciocínio, deve ser revista, já que existe uma nova relação entre o homem e a soma das informações que o rodeiam - e às vezes parecem afogá-lo hoje em dia. Até aqui o ser humano tem se relacionado com quantidades relativamente pequenas de informações, mas estamos no limiar do momento em que será possível, via redes globais de informação e comunicação, ter acesso a basicamente tudo o que se produz na área intelectual - como previu Vannevar Bush no seu famoso artigo, onde apresenta o sonho pioneiro que só virou realidade 50 anos depois com a World Wide Web (BUSH, 1991, op. cit.).

O que Bush não via com tanta clareza como hoje se vê é que o processo de construção do conhecimento é eminentemente coletivo, acontecendo na medida em que as pessoas produzem idéias interessantes e cheias de implicações teóricas e práticas, e interagem umas com as outras, criticando e depurando as idéias produzidas, assim procurando chegar mais perto da verdade. Mas essa limitação de sua visão foi prontamente corrigida por aqueles que o sucederam, como se há de mostrar nos capítulos subseqüentes, em especial no quarto.

\footnotetext{
${ }^{2}$ Hume afirma que há um princípio de conexão entre os diversos pensamentos ou idéias da mente, e que, ao surgirem num processo de lembrança ou imaginação, ligam-se uns aos outros com certo método e regularidade (HUME, 1999).
} 


\section{CONCLUSÃO}

As idéias e os dispositivos propostos por Vannevar Bush e seus descendentes, hoje apropriadamente chamados de tecnologias da inteligência, podem e devem exercer influência marcante numa nova educação. Não se trata de apenas mecanizar e automatizar processos de captura, armazenamento e busca de informação, como o fazem sistemas voltados para a gestão de dados e de informação. Trata-se, na verdade, do desenvolvimento do ser humano em sentido pleno, da expansão de sua inteligência, entendida no sentido mais amplo, mas abrangendo também a inteligência coletiva de que fala Lévy (LÉVY, 1993, op. cit.).

\section{REFERÊNCIAS}

ASSMANN, H. Reencantar a educação: rumo à sociedade aprendente. Petrópolis: Vozes, 1998. $251 \mathrm{p}$.

BUSH, V. As We May Think. In: NYCE, James M., KAHN, Paul (Orgs.). From Memex to hypertext: Vannevar Bush and the mind's machine. San Diego: Academic Press, 1991.

HUME, D. Investigação sobre o entendimento humano. São Paulo: editora UNESP, 1999. $212 \mathrm{p}$.

LÉVY, P. As tecnologias da inteligência. Rio de Janeiro: Editora 34, 1993. 203 p.

A inteligência coletiva. São Paulo: Loyola, 1999. 212 p.

MINSKY, M. The society of mind. New York, Simon \& Schuster, 1988. 339 p. 
